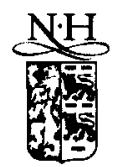

ELSEVIER

\title{
Real exchange-rate prediction over long horizons
}

\author{
Nelson C. Mark ${ }^{\mathrm{a}, *}$, Doo-Yull Choi ${ }^{\mathrm{b}}$ \\ ${ }^{a}$ Department of Economics, The Ohio State University, 410 Arps Hall, Columbus, OH 43210, USA \\ ${ }^{\mathrm{b}}$ Korea Economic Research Institute, FKI Bldg., 2801 Yoido-Dong, Yeongdungpo-ku, Seoul, \\ 150-756, South Korea
}

\begin{abstract}
In studying monthly real exchange rates between the US and Britain, Canada, Germany, and Japan from 1961 to 1993 , we find that the deviation of the log real exchange rate from its time-varying, long-run equilibrium value contains a statistically significant predictable component at the four-year horizon over a forecast period extending from 1985 to 1993. Fixed-effects regressions employing differentials in productivity, real interest rates, and per capita income display some predictive power but fundamentals based on simple monetary models are generally more accurate and significant. (C)1997 Elsevier Science B.V. All rights reserved.
\end{abstract}

Keywords: Real exchange rates; Fundamentals; Prediction; Long horizons

JEL classification: $\mathrm{F} 31 ; \mathrm{F} 47$

What accounts for real exchange-rate fluctuations? Until recently, the conventional and nihilistic view was that we did not know. Empirical research of the 1970s and 1980s, such as Roll (1979), Adler and Lehman (1983), Hakkio (1984), and Mark (1990), among others, that studied nominal exchange-rate and price level behavior during the modern float found little evidence against the hypothesis that the log real exchange rate followed a random walk. A common shortcoming of these studies, however, is that the time span of the data they analyze is short so short that reasonably reliable estimates and tests of long-run real exchange-rate dynamics are difficult to obtain.

The response of some researchers has been to employ longer series by extending

${ }^{*}$ Corresponding author. Tel.: +1 614292 0413; fax: + 1614292 3906; e-mail: mark.1@osu.edu. 
the data backwards in time. Two examples are Abuaf and Jorion (1990), who study the real exchange rate between the US and eight other countries from 1900 to 1972, and Lothian and Taylor (1996) who examine the real dollar-pound from 1791 to 1990 and real pound-French franc from 1803 to 1990 . Others, such as Frankel and Rose (1996) and Wu (1996) attempt to exploit information in the cross-section by pooling across currencies. These authors find that the autoregressive root in the log real rate is less than one. The tentative conclusions that we draw from these and other recent studies, therefore, is that purchasing-power parity (PPP) holds in the long run with the half-life of deviations estimated to lie between four and five years. 'A further implication is that the long-run value of the real exchange rate is constant, which is reasonable if macroeconomic volatility is due mainly to nominal shocks.

In this paper, we push beyond the idea that the long-run real exchange rate must either be constant or that it follows a random walk. Instead, we adopt a permanent-transitory decomposition in which the log real exchange rate co-trends with a set of nonstationary economic variables. The permanent, or unit root component, is estimated by cointegrating regression methods and is interpreted as the log real exchange rate's long-run equilibrium value. The implied transitory deviation from the long-run equilibrium is then employed in second-stage regressions to predict long-horizon changes in the real exchange rate. ${ }^{2}$ We work to improve estimation and prediction precision by modestly extending the data backwards and by pooling.

We entertain seven alternative specifications of the exchange rate's fundamental value. They are (i) the constant value implied by long-run PPP; (ii) $\log$ productivity differentials implied by Balassa (1964) and Samuelson (1964); (iii) productivity differentials combined with government consumption to income ratios suggested by the augmented Balassa-Samuelson model in Rogoff (1992); (iv) log real per capita income differentials implied by the equilibrium model in Lucas (1982); (v) ex ante real interest differentials implied by the canonical sticky price model in Dornbusch (1976); (vi) the deviation of the log nominal exchange rate from a linear combination of log money stock and log real income differentials, inspired by the expectation scheme of Frankel (1979), and (vii) a linear combination of differentials in log money and log real income that we motivate on empirical grounds.

We examine monthly observations of real exchange rates between the US dollar and the British pound (BP), Canadian dollar (CD), deutsche mark (DM), and the

\footnotetext{
'Edison (1987), Kim (1990), Diebold et al. (1991), Grilli and Kaminsky (1991) also find evidence in favor of long-run PPP from their analyses of long historical time series. The recent work on PPP is too extensive to cite in its entirety here. For excellent surveys on the current state of PPP research see Breuer (1994), Bleaney and Mizen (1995), Froot and Rogoff (1996), and Rogoff (1995).

${ }^{2}$ We emphasize prediction accuracy at the four-year horizon because, as in studies of nominal exchange-rate behavior (e.g. Chinn and Meese, 1995; Mark, 1995) it is necessary to look at long horizon changes before evidence of predictability begin to show up.
} 
yen (JY) from 1961:01 to 1993:11. Out-of-sample predictions are generated by recursive updating throughout a fixed forecast period extending from 1985:01 to 1993:11. As suggested by recent work on long-run PPP, we work on maximizing the sample size by employing observations prior to the float and by pooling across currencies to improve the precision of our estimates and forecasts. We investigate the role of the time span of the sample employed in estimation by first computing forecasts with regressions estimated on data available since the move to generalized floating on 1973:03. These forecasts are then compared to predictions from regressions fitted on data going back to 1961 . The benefits of pooling are studied by comparing predictions from least-squares regressions to those generated by fixed-effects regressions. We measure forecast accuracy by mean square prediction error (MSPE) and conduct asymptotic inference with a test of predictive accuracy from Diebold and Mariano (1995).

We can summarize our main findings from the out-of-sample prediction exercise here. First, for a given formulation of the fundamental value, we generally get more accurate predictions when pre-float observations are employed in estimation. This occurs in spite of the fact that the sample spans two separate regimes and underscores the point that many empirical studies of real exchange rate behavior over the float are unable to obtain reliable parameter estimates because the time span of the data they use is not sufficiently long. Second, only the fundamentals implied by monetary models display evidence of predictive power in the leastsquares forecasts. Point predictions from least-squares regressions using productivity differentials and real interest-rate differentials fail to beat the random walk. Third, pooling generally leads to better forecasts. We find that point predictions from fixed-effects regressions using differentials in productivity, real interest rates, and per capita income are more accurate than the random walk but forecasts that exploit the monetary model fundamentals continue to be more accurate and significant. Relative to the driftless random walk, the root MSPEs at the four-year horizon under the ad hoc monetary model estimated from 1961 are $0.76,0.57,0.69$, and 0.62 for the real $\mathrm{BP}, \mathrm{CD}, \mathrm{DM}$, and JY respectively.

We also study the relation between deviations of exchange rates from their fundamental values and changes in the log real exchange rate over the full sample. Regressions of 3,12,24, 36, and 48-month ahead changes in the log real exchange rate on its deviation from the monetary-model fundamentals and from the productivity differential fundamentals display a familiar pattern - the slope coefficients, asymptotic $t$-ratios, and $R^{2}$ increase with horizon. ${ }^{3}$ Under the ad hoc monetary model, lengthening the forecast horizon from 3 to 48 months in the fixed-effect regressions results in an increase of the slope coefficient from 0.04 to 0.58 , the asymptotic $t$-ratios from 4.9 to 11.2 , and the $R^{2}$ from 0.02 to 0.27 for the

\footnotetext{
${ }^{3}$ The positive relation between horizon and these regression estimates has been found in equity returns by Campbell and Shiller (1988) and Fama and French (1988), and in log nominal exchange rates by Mark (1995).
} 
real $\mathrm{BP}, 0.05$ to 0.46 for the real $\mathrm{CD}, 0.06$ to 0.52 for the real $\mathrm{DM}$, and 0.06 to 0.60 for the real JY.

We need to be circumspect in evaluating the asymptotic $t$-ratios from the long-horizon regression, however. A problem arises because changes in the log real exchange rate at horizons exceeding the sampling interval $(k>1)$ of the observations are used as the dependent variable which induces $(k-1)$-th order serial correlation into the error term. As Hodrick (1992) and Nelson and Kim (1993) have shown for the least squares case, the asymptotic distribution of heteroskedastic and autocorrelation consistent $t$-ratios can differ considerably from their exact finite sample distributions when the extent of the overlap is large relative to the sample size. To bypass this problem, we examine regressions of the one-period change in the log real exchange rate on the $k$-period moving average of the regressor as suggested by Jegadeesh (1991). The numerator of the slope coefficient in Jegadeesh's 'backward average' regression is the same as that in the long-horizon regression. Consequently, we can test the hypothesis that the real exchange rate is unpredictable by testing whether the backward-average regression slope coefficient is zero, and because real exchange-rate changes are taken at the same frequency with which the data are sampled, no artificial serial correlation is induced into the error term. As shown in Hodrick's Monte Carlo study, the asymptotic distribution of the least-squares $t$-ratio from the backward average regression is reasonably close to the empirical distribution and we draw on his results to justify doing asymptotic inference in our analysis of the backward average regressions. This analysis allows us to easily reject the hypothesis that the log real exchange rate is unpredictable at standard significance levels. ${ }^{4}$

The remainder of the paper is as follows. The next section shows how popular theories of exchange-rate determination motivate the various regressions that we consider. Econometric considerations are discussed in Section 2. The empirical results are discussed in Section 3 and concluding remarks are contained in Section 4.

\section{Organizing principles}

At date $t$, let $S_{t}$ be the domestic currency price of one unit of the foreign currency, $P_{t}$ be the domestic price level, and $P_{t}^{*}$ be the foreign price level. We

\footnotetext{
${ }^{4} \Lambda$ nother option for us would be to draw inferences from bootstrap distributions of the relevant test statistics. The pitfall in this strategy is that the bootstrap is built upon estimates of an unknown data generating process (DGP) so unless we are reasonably sure that the estimated DGP is 'close' to the true DGP, we cannot be sure that bootstrap inferences will be any more reliable than asymptotic inference. In addition, the fundamental values that we employ in our regressions are themselves estimated so a bootstrap analysis would require that we also model the processes governing each of the individual time series used in constructing the fundamental value. In light of these complications, we are doubtful of our ability to model the true DGP with sufficient accuracy.
} 
define the log real exchange rate as $q_{t} \equiv \ln \left(S_{t} P_{t}^{*} / P_{t}\right)$, which we interpret as the log relative price of the home country's representative commodity basket in terms of the foreign country's basket.

It is convenient to decompose $q_{t}$ as

$$
q_{t}=\bar{q}_{i}-z_{i}
$$

where $\bar{q}_{t}$ is the fundamental (or long-run equilibrium) value and $z_{t}$ is an error term. Alternative views of the real exchange-rate process are conveniently nested in Eq. (1). For example, under the random walk model, we could have $\bar{q}_{t}=\bar{q}_{t-1}+\omega_{t}$, with $\left\{\omega_{t}\right\}$ a serially uncorrelated sequence and $\operatorname{var}\left(z_{t}\right)=0$. Alternatively, long-run PPP can be represented with a constant valued $\bar{q}$ and $\left\{z_{t}\right\}$ being a serially correlated covariance stationary sequence.

In this paper, we take the random walk and long-run PPP as points of departure. As in Huizinga (1987) and Cumby and Huizinga (1991), we pursue a middle ground in which $\left\{q_{t}\right\}$ contains both a unit-root or permanent component $\left\{\vec{q}_{t}\right\}$ and a transitory part $\left\{z_{t}\right\}$; and like Cumby and Huizinga, Eichenbaum and Evans (1995) and Rogers (1995), we bring in data other than the exchange rate to model its long-run behavior. We entertain six alternative formulations of $\left\{\bar{q}_{t}\right\}$. Five of these formulations are theoretically motivated fundamental values of the log real exchange rate while one is ad hoc and motivated largely on empirical grounds. We also consider a formulation that departs from Eq. (1) in that we take $z$, to be the deviation of the $\log$ nominal exchange rate, $s_{t}$, from its fundamental value, $\bar{s}_{t}$.

Given a representation for $\left\{\bar{q}_{t}\right\}$ (or $\left\{\bar{s}_{t}\right\}$ ), which we estimate using cointegrating regression methods, we condition on $z_{t}$ and run the $k$-period regression

$$
q_{t+k}-q_{t}=\alpha_{k}+\beta_{k} z_{t}+v_{t, k} .
$$

As can be seen, Eq. (2) is a restricted error-correction model. At any instant, $q_{t}$ will deviate from its theoretically implied fundamental value $\bar{q}$, but if the theory has empirical content, $q_{t}$ will move towards $\bar{q}_{t}$ over time. It is this convergence property that we attempt to exploit in prediction.

We emphasize that the main thrust of the paper is to establish and to explore the relation between current valued fundamentals and future changes in the log real exchange rate. We draw on some popular models of exchange-rate determination to guide our choice of these fundamentals, but tests of any particular theory are beyond the scope of this paper.

For notational efficiency, let $x^{\mathrm{e}}$ denote people's expected value of $x, x^{*}$ denote the value of $x$ in the foreign country, and $\tilde{x}=x-x^{*}$ denote the domestic-foreign differential in $x$. We now describe our candidate specifications for $\bar{q}_{t}$.

\subsection{Purchasing-power parity}

Under purchasing-power parity, the fundamental value of the real exchange rate, $\bar{q}$, is constant. This is the one formulation where we work under the assumption 
that $\left\{q_{t}\right\}$ is stationary. We entertain long-run PPP as a point of comparison for our alternative formulations that allow the fundamental value to vary over time.

\subsection{Balassa-Samuelson models}

Consider an economy that produces traded and non-traded goods. Let the log price level be $p=\theta p^{\mathrm{T}}+(1-\theta) p^{\mathrm{N}}$ where $p^{\mathrm{T}}$ is the log home price of tradables, $\theta$ is the domestic consumption share of tradables, and $p^{\mathrm{N}}$ is the log home price of nontradables. The $\log$ real exchange rate can be decomposed into the log real exchange rate for traded goods, the log relative price between tradables and nontradables at home, and the log relative price between tradables and nontradables abroad. That is,

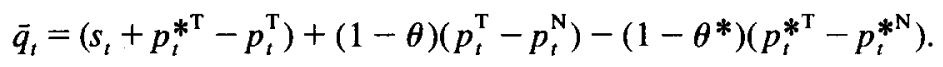

Under the Balassa (1964)-Samuelson (1964) framework, the real exchange rate is determined entirely by the production technology if (i) the law of one price holds among traded goods so that the first term in Eq. (3) vanishes; (ii) the terms of trade are fixed; (iii) capital markets are internationally integrated; (iv) there are constant returns to scale in production; and (v) factors are mobile between sectors. Since nontradables have a heavy service component and are generally produced with labor intensive methods, productivity growth should be concentrated in the tradables sector. This implies that high growth countries will experience real appreciations over time because productivity growth will raise the economy-wide real wage and lower the relative price of tradables, $p_{t}^{\mathrm{T}}-p_{t}^{\mathrm{N}}$. As can be seen in Eq. (3), this causes $q_{t}$ to fall.

We take (log) manufacturing production divided by manufacturing employment as our measure labor productivity in the tradables sector, $a_{t}^{T}$. Because data on nontradables are not readily available, we follow Rogoff (1992) and Chinn (1994) in assuming that nontradable sector productivity growth is zero and represent the fundamental value under the productivity approach as

$$
\bar{q}_{t}=\gamma_{0}+\gamma_{1} \tilde{a}_{t}^{\mathrm{T}} .
$$

We also examine the modified Balassa-Samuelson model in Rogoff (1992) where intersectoral factor immobility and poor international capital market integration are assumed. In addition to productivity differentials, Rogoff demonstrates that the real exchange rate depends on aggregate demand factors which he measures with government expenditures. If a high proportion of government spending goes towards nontraded goods, higher spending drives up the relative

\footnotetext{
${ }^{5}$ The productivity approach to real exchange-rate determination has been investigated empirically by Hsieh (1982), Engel (1993), DeGregorio and Wolf (1994), Kakkar and Ogaki (1994), and Rogers and Jenkins (1995).
} 
price of nontraded goods and, by Eq. (3), leads to a real appreciation. ${ }^{6}$ Following Rogoff, we use the ratio of government consumption to income $g_{t}$ to measure the aggregate demand variable, where

$$
\bar{q}_{t}=\gamma_{0}+\gamma_{1} \tilde{a}_{t}^{\mathrm{T}}+\gamma_{2} \tilde{g}_{t}
$$

\subsection{Representative agent general equilibrium models}

We draw on Lucas (1982) as our canonical general equilibrium model. We imagine an endowment economy with complete risk sharing where $Y_{t}$ is the non-storable output of the home good and $Y_{i}^{*}$ is the non-storable output of the foreign good. Let $C_{1, t}$ be the domestic agent's consumption of the home good and $C_{2, t}$ be her/his consumption of the foreign good. Foreign consumption of the home and foreign endowments are $C_{1, t}^{*}=Y_{t}-C_{1, t}$ and $C_{2, t}^{*}=Y_{t}^{*}-C_{2, t}$ respectively. Let the domestic agent's period utility function be $U\left(C_{1, t}, C_{2, t}\right)=\theta C_{1, t}^{(1-\gamma)} /(1-\gamma)+$ $(1-\theta) C_{2, r}^{(1-\gamma)} /(1-\gamma)$. In the pooling equilibrium with equal wealth at home and abroad, equilibrium consumption of the two goods is determined by the sharing rules, $C_{1, t}=C_{1, t}^{*}=Y_{t} / 2$ and $C_{2, t}=C_{2, t}^{*}=Y_{t}^{*} / 2$, and the real exchange rate, $\bar{Q}_{t}$, is given by the marginal rate of substitution between the home and foreign good, $\bar{Q}_{t}=U_{2}\left(c_{1, t}, c_{2, t}\right) / U_{1}\left(c_{1, t}, c_{2, t}\right)=[(1-\theta) / \theta]\left(Y_{t} / Y_{t}^{*}\right)^{\gamma}$. Taking logarithms of both sides of this last equation yields

$$
\bar{q}_{t}=\gamma_{0}+\gamma_{1} \tilde{y}_{t}^{\mathrm{p}},
$$

where $\gamma_{0}=\ln [(1-\theta) / \theta], \gamma_{1}=\gamma, \bar{q}_{t} \equiv \ln \left(\bar{Q}_{t}\right)$, and $\tilde{y}_{t}^{\mathrm{p}} \equiv \ln \left(Y_{t}\right)-\ln \left(Y_{t}^{*}\right)$ (and the $\mathrm{p}$ superscript indicates per capita measures).

Eq. (6) serves as our fourth representation of the log real exchange rate's equilibrium fundamental value?

\subsection{Real interest-rate differentials}

Sticky price models imply that the expected real depreciation is determined by the ex ante real rate interest differential, $\tilde{r}_{t}^{e .8}$. For example, in the discrete-time

${ }^{6}$ Rogoff empirically investigates the fixed-factors model for the real dollar-yen rate with mixed success. Chinn (1994) examines it for the same currencies as we do and finds some support for the real dollar-yen rate. DeGregorio and Wolf (1994) extend the productivity approach to allow for terms of trade fluctuations.

${ }^{7}$ The separable formulation of utility is used mainly for convenience in exposition. When utility is given by $U\left(c_{1, t,}, c_{2, t}\right)=x_{t}^{(1-\gamma)} /(1-\gamma)$ with $x_{t}=C_{t} / C_{t}^{1-\delta}, C_{t}=y_{t}^{\theta} y_{t}^{*(1-\theta)}$ as in Abel $(1990)$, or $x_{t}=C_{t}+\delta C_{t-1}$ and $C_{t}=y_{i}^{\theta} y_{t}^{*(1-\theta)}$ as in Eichenbaum et al. (1988), one obtains the same implication for the equilibrium real exchange rate when period utility is non separable due to durability $(\delta>0)$ or habit formation $(\delta<0)$.

${ }^{8}$ Obstfeld (1993) argues that correlations between real exchange rates and real interest-rate differentials cannot be used to discriminate between sticky and flexible price models. He presents a two-sector model with tradable and nontradable goods with fully flexible prices and wages in which the real exchange rate is positively correlated with the real interest-rate differential. 
analog of Dornbusch (1976), log real exchange-rate dynamics are given by $q_{t+k}^{\mathrm{e}}-q_{t}=\theta_{k}\left(q^{\mathrm{f}}-q_{t}\right)$, where $q^{\mathrm{f}}-q_{t}=\left(1 / \theta_{k}\right) \tilde{r}_{t}^{\mathrm{e}}, q_{t}$ is the instantaneous log real exchange rate, $q^{\mathrm{f}}$ is its theoretical long-run equilibrium value, $\theta$ is the speed of adjustment coefficient, and $\theta_{k}=1-e^{-\theta k}$. A shock will cause $q_{t}$ to deviate from $q^{f}$ but because goods market adjustment takes time, the deviation will persist. Dornbusch's model contains a complete theory of the deviation of the exchange rate from its long-run fundamental value, but because it has previously been intensively studied with relatively little success by other researchers, we do not explore this particular relationship ${ }^{9}$. Instead, we view the theory's instantaneous real exchange rate, $q_{\mathrm{t}}=q^{\mathrm{f}}+\left(1 / \theta_{k}\right) \tilde{r}_{l}^{\mathrm{e}}$, as the fundamental value from which we measure real exchange-rate deviations. The forgoing considerations motivate our fifth representation,

$$
\bar{q}_{t}=\gamma_{0}+\gamma_{1} \tilde{r}_{t}^{\mathrm{e}},
$$

where $\gamma_{0}=q^{\mathrm{f}}$, and $\gamma_{1}=-1 / \theta^{k}$.

\subsection{Monetary models}

Frankel (1979) generalizes the expectational scheme of Dornbusch (1976) to account for steady state inflation. In discrete time, his rule is:

$$
s_{t+k}^{\mathrm{e}}-s_{t}=\theta_{k}\left(\bar{s}_{t}-s_{t}\right)+\tilde{\pi}_{t+k, t}^{\mathrm{e}},
$$

where $s$ is the $\log$ nominal exchange rate, $\tilde{\pi}_{t+k, t}^{\mathrm{e}}$ is the date $t$ expected inflation differential from $t$ to $t+k, \theta$ is the speed of adjustment coefficient, $\theta_{k}=1-e^{-\theta k}$, and $\bar{s}_{t}$ is the fundamental value of the log nominal exchange rate. In the steady state $s_{t}=\bar{s}_{t}$ but the expected depreciation is not zero unless the steady state inflation differential is expected to be zero as well. Subtracting $\tilde{\pi}_{t+k, t}^{\mathrm{e}}$ from both sides of Eq. (8) yields

$$
q_{t+k}^{\mathrm{e}}-q_{t}=\theta_{k}\left(\bar{s}_{t}-s_{t}\right) \text {, }
$$

which implies that the expected $k$-period real depreciation is proportional to the deviation of the log nominal exchange rate from its fundamental value.

Frankel advanced his model of expectations to describe behavior in a regime of flexible exchange rates. Under a peg where the authorities fix $s_{t}$, we view $\bar{s}_{t}$ as the shadow nominal exchange rate - the hypothetical long-run equilibrium value that the nominal rate would be under a free float. Eq. (8) says that if the current regime is credible $\left(s_{t+k}^{\mathrm{e}}=s_{t}\right)$, the steady state requires that the expected inflation

${ }^{9}$ For example, Meese and Rogoff (1988) examine its ability to predict out-of-sample, Campbell and Clarida (1987) and Edison and Melick (1995) study the linkage in sample, and Edison and Pauls (1993) and Baxter (1994) search for long-run linkages. 
differential be zero. To illustrate, suppose we get a negative aggregate demand shock that leads to a real depreciation. Since the aggregate price level is momentarily fixed, the shock raises $\bar{s}_{f}$, driving us away from the steady state. In order for the regime to remain credible, the authorities must accommodate the required real depreciation say by engineering a future deflation at home so that people expect a lower inflation differential. On the other hand, if the current regime is not credible, some or all of the adjustment may be expected to take place through a future devaluation.

To make Eq. (9) operational, we utilize the standard monetary model fundamentals and set

$$
\bar{s}_{t}=\tilde{m}_{t}-\gamma_{2} \tilde{y}_{t},
$$

where $\tilde{m}_{t}$ is the log money differential, $\tilde{y}_{t}$ is the log real income differential, and the homogeneity of degree one between money and the nominal exchange rate is imposed by constraining the coefficient on $\tilde{m}_{t}$ to be one. The prediction equation is then the regression of $q_{t+k}-q_{t}$ on $z_{t}=\bar{s}_{t}-s_{t}$.

For our final formulation, we let

$$
\bar{q}_{t}=\tilde{m}_{t}-\gamma_{2} \tilde{y}_{t}
$$

with $z_{t}=\bar{q}_{t}-q_{t}$. Considering the success that Mark (1995) finds in using the monetary-model fundamentals, $\tilde{m}_{t}-\gamma_{2} \tilde{y}_{t}$, for predicting the log nominal exchange rate combined with the fact that $\log$ nominal and real exchange-rate movements are highly positively correlated, investigating the ability of Eq. (11) to predict log real exchange rates is not an obviously foolish thing to do..$^{10}$ Although sufficient amounts of torture can induce equilibrium models such as that of Hodrick (1989) to cough up our last representation, our principal motivation is empirical and we will refer to Eq. (11) as the 'ad hoc monetary model' fundamental."

\footnotetext{
${ }^{10}$ We report these correlations in our data set below. In addition, Mussa (1986) and Mark (1990) have emphasized the similarity in the behavior of nominal and real exchange rates.

"Under very restrictive assumptions, it is possible to obtain Eq. (11) as the equilibrium real exchange rate from an equilibrium model. For example, Hodrick (1989) considers a two-country cash-in-advance model with domestic and foreign governments. Letting the period utility of the representative agent (which is defined over consumption of the domestic $\left(C_{1, t}\right)$ and the foreign $\left(C_{2, l}\right)$ goods) be $U\left(C_{1, t}, C_{2, l}\right)=$ $C_{1,2}^{(1-\gamma)} /(1-\gamma)+C_{2, t}^{(1-\delta)} /(1-\delta)$, the rcal exchange rate given in eq. 17 of his paper is $\lambda_{t}^{-1} 2^{\delta} E_{t}[(1-$ $\left.\left.G_{2, t+1} / Y_{2, t+1}\right)^{-\delta} Y_{2, t+1}^{1-\delta} M_{2, t} /\left(Y_{2, t} M_{2, t+1}\right)\right]$ where $\lambda_{t}=2^{\gamma} E_{t}\left[\left(1-G_{1, t+1} / Y_{1, t+1}\right)^{-\gamma} Y_{1, t+1}^{1-\gamma} M_{1, t} /\left(Y_{1, t} M_{1, t+1}\right)\right]$, and $Y_{i, r}, G_{i, r}$, and $M_{i, r}$ are country $i$ 's $(i=1,2)$ endowment, government's purchases, and money stocks at date $t$. If we assume that the two curvature parameters are equal $(\gamma=\delta)$, purchases are proportional to the endowment $\left(G_{i, r}=c_{i} Y_{i, l}\right)$, the log endowments follow a Gaussian $\operatorname{AR}(1)$ process with its root inside the unit circle $\left(\ln Y_{i, r}=\rho_{y} \ln Y_{i, t-1}+\varepsilon_{i, t}, \varepsilon \sim N\left(0, \sigma_{\varepsilon}^{2}\right), \rho_{y}>1\right)$, and $\log$ money follows the Gaussian AR(1) process with root equal to $1 / 2\left(\ln M_{i, t}=(1 / 2) \ln M_{i, t-1}+u_{i, t}, u_{i, r} \sim N\left(0, \sigma_{u}^{2}\right)\right)$, we obtain Eq. (11) in the text as the equilibrium log real exchange rate.
} 


\section{Econometric framework}

The empirical fundamental values depend on estimates of unknown parameters. Section 2.1 describes how these estimates are obtained. The long-horizon and the backward averaged regressions are discussed in Section 2.2. Section 2.3 describes the generalized method of moments procedure we use to estimate the fixed-effects regression.

\subsection{Constructing fundamental values}

Under long-run PPP, we estimate the fixed fundamental value with the sample mean, $\hat{\bar{q}}=\frac{1}{T} \sum_{t=1}^{T} q_{t}$. Under the other specifications, we take as a maintained assumption that both $\left\{q_{t}\right\}$ (or $\left\{s_{t}\right\}$ in the Frankel specification) and the elements of $\left\{x_{r}\right\}$ contain unit roots, but are co-integrated so that the sequence $\left\{z_{t}\right\}$ is covariance stationary. We do not apply formal tests for the existence of a unit root in $\left\{z_{t}\right\}$ since as Cochrane (1991) and Blough (1992) argue, the application of generic unit root tests in finite samples may be pointless. ${ }^{12}$

For those specifications that do not involve real interest rates, the first step is to estimate the cointegrating vector for $\left\{q_{t}, x_{t}^{\prime}\right\}$. We use $x_{t}^{\prime}=\left(1, \tilde{a}_{t}^{T}\right)$ for the productivity approach, $\left.x_{t}^{\prime}=\left(1, \tilde{a}_{t}^{T}, \tilde{g}_{t}\right)\right)$ for Rogoff's augmented productivity approach, $x_{t}^{\prime}=$ $\left(1, \tilde{y}_{t}^{\mathrm{p}}\right)$, for the equilibrium approach, and $x_{t}^{\prime}=\left(1, \tilde{m}_{t}, \tilde{y}_{t}\right)$ for the monetary models. The cointegrating vector, $\gamma$, is estimated with the dynamic ordinary least squares (OLS) of Stock and Watson (1993) using three lead and lagged changes of $x_{t}$. The estimated fundamental value is then $\hat{\bar{q}}_{t}=x_{t}^{\prime} \hat{\gamma}$, and the conditioning information employed in the long-horizon regression is simply

$$
\hat{z}_{t}=x_{i}^{\prime} \hat{\gamma}-q_{i}
$$

(To construct $\bar{s}_{t}$ we replace $q_{t}$ with $s_{t}$ in the dynamic OLS regression.)

The real interest-rate differential fundamental requires an additional round of estimation to measure inflationary expectations. Let $\tilde{i}_{t, k}$ be the date $t$ nominal yield differential between domestic and foreign assets with comparable default risk maturing at date $t+k$. Assume that people form their expectations of the inflation differential rationally so that

$$
\tilde{\pi}_{t+k, k}=\tilde{\pi}_{t, k}^{\mathrm{e}}+v_{t, k},
$$

where $v_{t, k}$ is the rational prediction error realized at $t+k$. Following Mishkin (1981), Cumby (1988), and Cumby and Huizinga (1991), we represent the unobserved expected inflation differential as the sum of its linear projection onto a vector of date $t$ information, $V_{t}$, and a projection error, $u_{t}$,

\footnotetext{
${ }^{12}$ In particular, Blough shows that for any finite sample, the maximal local power of generic unit root tests is equal to the size of the test.
} 


$$
\tilde{\pi}_{t, k}^{\mathrm{e}}=\boldsymbol{V}_{t}^{\prime} \boldsymbol{\lambda}+u_{t}
$$

where $\lambda$ is the vector of projection coefficients. Substituting Eq. (14) into Eq. (13) yields

$$
\tilde{\pi}_{t+k, k}=\boldsymbol{V}_{t}^{\prime} \boldsymbol{\lambda}+\eta_{t, k},
$$

where the composite error $\eta_{t, k}=\nu_{t, k}+u_{t}$ is orthogonal to $V_{t}$. We estimate $\lambda$ using Stock and Watson's dynamic OLS with three lead and lagged changes in $\boldsymbol{V}_{t}$ and measure expected inflation with

$$
\hat{\tilde{\pi}}_{t, k}^{\mathrm{e}}=\boldsymbol{V}, \hat{\boldsymbol{\lambda}} \text {. }
$$

We then set $x_{t}=\left[1,\left(\tilde{i}_{t, k}-\hat{\tilde{\pi}}_{t, k}^{\mathrm{e}}\right)\right]$ and estimate $\bar{q}_{t}$ as outlined above.

The information that we use for $V_{t}$ is the nominal interest-rate differential, $\tilde{i}_{t, k}$, and a weighted moving average of the domestic-foreign differential in (a) monetary growth rates, (b) income growth rates, and (c) three-month inflation rates. These averages are taken over the previous twelve months with geometrically declining weights.

\subsection{Long-horizon and backward averaged regressions}

In what has become standard protocol for model validation in empirical exchange-rate research, we examine the out-of-sample accuracy of the alternative long-horizon regression forecasts (Eq. (2)) relative to the benchmark 'no change' prediction of the driftless random walk model. We generate dynamic point predictions by recursively updating the sample through the forecast period for both the long-horizon prediction regressions as well as for the preliminary regressions used to construct the fundamental values. We then rank these point predictions according to their root MSPEs and use the Diebold and Mariano (1995) test of the hypothesis that the difference between the mean square prediction errors from the two models is zero. ${ }^{13}$

We know that it is important to get data over a sufficiently long time span in order to obtain reliable parameter estimates. Since the prediction experiment necessarily makes use of only a portion of the available data, we do not want to rely entirely on these results. To examine issues about real exchange-rate predictability, we can test hypotheses concerning the long-horizon slope coeffi-

${ }^{13}$ Let $t_{0}$ be the date at which the first forecast is formed, $\nu_{i, t},(i=1,2)$ be the prediction error of model $i$, $N_{\mathrm{f}}=T-t_{0}-k+1$ be the number of forecasts, $\bar{d}=\left(1 / N_{\mathrm{f}}\right) \Sigma_{t=t_{\mathrm{f}+k}}^{r}\left(\nu_{1, t}^{2}-\nu_{2, t}^{2}\right)$ be the sample mean squared error differential and $f_{\mathrm{d}}(0)$ be the spectral density of $\left\{\nu_{1, f}^{2}-\nu_{2, t}^{2}\right\}$ at frequency 0 . Diebold and Mariano's test statistic is

$$
\mathscr{D} \mathfrak{M}=\bar{d} \sqrt{\left(2 \pi \hat{f}_{\mathrm{d}}(0) / N_{\mathrm{f}}\right)}
$$

We estimate $f_{\mathrm{d}}(0)$ by Newey and West (1994). Under the null hypothesis of equal forecast accuracy, the mean square error differential is zero and $\mathscr{D} M$ has an asymptotic standard normal distribution. 
cient estimated over the full sample. But as mentioned in the introduction, tests based on asymptotic $t$-ratios from the long-horizon regressions have been shown to suffer from substantial small-sample size distortion. The reformulation by Jegadeesh (1991) avoids this problem by regressing ( $k$ times) the one period change in the log real exchange rate, $q_{t+1}-q_{t}$ on a $k$-period moving average of past values of the predictor, $z_{t}$,

$$
k\left(q_{t+1}-q_{t}\right)=\alpha+\phi_{k}\left(\frac{1}{k} \sum_{j=0}^{k-1} z_{t-j}\right)+\epsilon_{t+1} .
$$

The numerator of the slope coefficient $\phi_{k}$ in Eq. (17) and $\beta_{k}$ in Eq. (2) are identical in population. Thus, a test of $k$-period horizon predictability of the log real exchange rate can be performed by testing the hypothesis that the slope coefficient $\phi_{k}=0$ in Eq. (17). ${ }^{14}$

While artificial serial correlation is not induced into the error term, there is no guarantee that it is in fact serially uncorrelated. Consequently, we construct serial correlation and conditionally heteroskedastic consistent asymptotic $t$-ratios by Newey and West (1994). ${ }^{15}$

\subsection{Fixed-effects estimation}

Let the $n$ currencies be indexed by $j=1, \ldots, n$. For the $k$-horizon fixed-effects regression, we constrain the slope coefficients to be equal across currencies and we estimate the $n+1$ coefficients $\left(\alpha_{k}^{j}, \beta_{k}\right), j=1, \ldots, n$. The vector of orthogonality conditions used in estimation is $\boldsymbol{h}_{t}=\left[\nu_{t, k}^{l}\left(1, z_{t}^{1}\right), \ldots, \nu_{t, k}^{n}\left(1, z_{t}^{n}\right)\right]^{\prime}$. For the backward average regression, let $\bar{z}_{t, k}^{j}=(1 / k) \sum_{i=0}^{k-1} z_{t-i}^{i}$ be country $j$ 's $k$-period moving average of current and past values of $z_{t}^{j}$. The vector of orthogonality conditions that we use in estimation of the backward average regression is $\boldsymbol{h}_{f}=$ $\left[\epsilon_{t+1}^{1}\left(1, \bar{z}_{t}^{1}\right), \ldots, \epsilon_{t+1}^{n}\left(1, z_{t}^{n}\right)\right]^{\prime}$.

\footnotetext{
${ }^{14}$ Hodrick (1992) conducts a Monte Carlo study of the small sample propertics of OLS for the long-horizon and backward average regressions using a sample size $T=431$ in the data generating process (DGP). He considers Newey and West (1987) asymptotic $t$-ratios with zero lags and with twelve lags in the backward average regressions. While he finds that there is a moderate amount of size distortion in the asymptotic tests, the empirical distribution of the $t$-ratios from the backward average regressions are reasonably close to the asymptotic distributions. Hodrick reports that the empirical critical level of a one-tail test of the null is approximately 2.0 at each of the horizons that he examines. Since we have 395 observations, nearly the same number as Hodrick used, we bear his findings in mind when conducting inference. We do so with some caution, however, as his analysis strictly pertains only to a particular parameterization of the DGP.

${ }^{15}$ The guts of their lag selection procedure is as follows: Let $\hat{\nu}_{t+k, t}$ be the scalar residual, let $z_{t}$ be an $l \times 1$ vector of regressors with a constant as its first element, let $\hat{h}_{t} \equiv z_{t} \hat{\nu}_{t+k, t}$, set $n=\left[4(T / 100)^{(2 / 9)}\right]$, where $\left[x \boldsymbol{l}\right.$ is the integer part of $x$. For $j=0,1, \ldots, n$ we compute $\sigma_{j+1}=[1 /(T-1)] \Sigma_{t=j+2}^{T}\left(\omega^{\prime} h_{t}\right)\left(\omega^{\prime} h_{t-j}\right)$, $s_{1}=2 \Sigma_{j=1}^{n} j \sigma_{j+1}, s_{0}=\sigma_{0}+2 \Sigma_{j=1}^{n} \sigma_{j+1}$. The truncation lag is given by the rule, $m=\left\{1.1447\left[\left(s_{1} /\right.\right.\right.$ $\left.\left.\left.s_{0}\right)^{2}\right]^{1 / 3} T^{1 / 3}\right\}$. Newey and West suggest pre-whitening the observations $\left\{h_{t}\right\}$, but we found that this made little difference in the results. The results reported in the text were calculated without pre-whitening.
} 
We choose the parameter vector of the system, $\eta$, to minimize

$$
\left(\frac{1}{T} \sum_{t=1}^{T} \boldsymbol{h}_{t}\right)^{\prime} S_{T}^{-1}\left(\frac{1}{T} \sum_{t=1}^{T} \boldsymbol{h}_{t}\right)
$$

where $S_{T}$ is a consistent estimator of the spectral density matrix of $\boldsymbol{h}_{\boldsymbol{t}}$ at frequency zero. We set $S_{T}=\Omega_{T, 0}+\sum_{j=1}^{m}[1-j /(m+1)]\left(\Omega_{T, j}+\Omega_{T, j}\right)$ with $m$ chosen by the Newey and West (1994) procedure, $\Omega_{T, j}=(1 / T) \sum_{t=1}^{T} \boldsymbol{h}_{t} \boldsymbol{h}_{t-j}^{\prime}$, and $D_{T}=(1 /$ $T) \Sigma_{t=1}^{T}\left[\partial \boldsymbol{h}_{t}\left(\boldsymbol{\eta}_{T}\right) / \partial \boldsymbol{\eta}\right]$. Then the asymptotic covariance matrix of the generalized method of moments (GMM) estimator, $\boldsymbol{\eta}_{T}$, is estimated by

$$
\operatorname{var}\left(\boldsymbol{\eta}_{T}\right)=\frac{1}{T}\left(D_{T}^{\prime} S_{T}^{-1} D_{T}\right)^{-1}
$$

\section{Empirical results}

We take a first look at the data in Table 1 which reports sample means, standard deviations, and the contemporaneous correlation between percentage changes in nominal and real exchange rates. The calculations are made for horizons of 1 and 48 months (the complete data set is described in $\Lambda$ ppendix A).

We make three comments in regard to the table. First, changes in log real and $\log$ nominal exchange rates are highly correlated not only at the 1-month horizon, but also at the 48 -month horizon. Because nominal exchange rates changed less frequently during the pre-float period, the correlation is naturally lower during this subperiod than during the float. Second, changes in log real and log nominal exchange rates are about equally volatile. Both nominal and real exchange-rate changes exhibited substantially less volatility during the pre-float period. Third, by examining the mean changes, it can be seen that log levels of nominal and real exchange rates generally evolved in the same direction. The real pound is the exception where over the float, the dollar fell against the pound in nominal terms (mean 1-month change in log nominal exchange rate $=0.041$ ) but gained in real terms (mean 1-month change in log real exchange rate $=-0.206$ ).

The four log real and log nominal exchange rates that we study are plotted in Figs. 1-4. The nominal and real rates converge on the common base date used in constructing the price indices.

\subsection{Least-squares out-of-sample forecasts}

In keeping with our emphasis on long horizons, we assess out-of-sample prediction accuracy of the alternative regressions at the 48-month forecast 


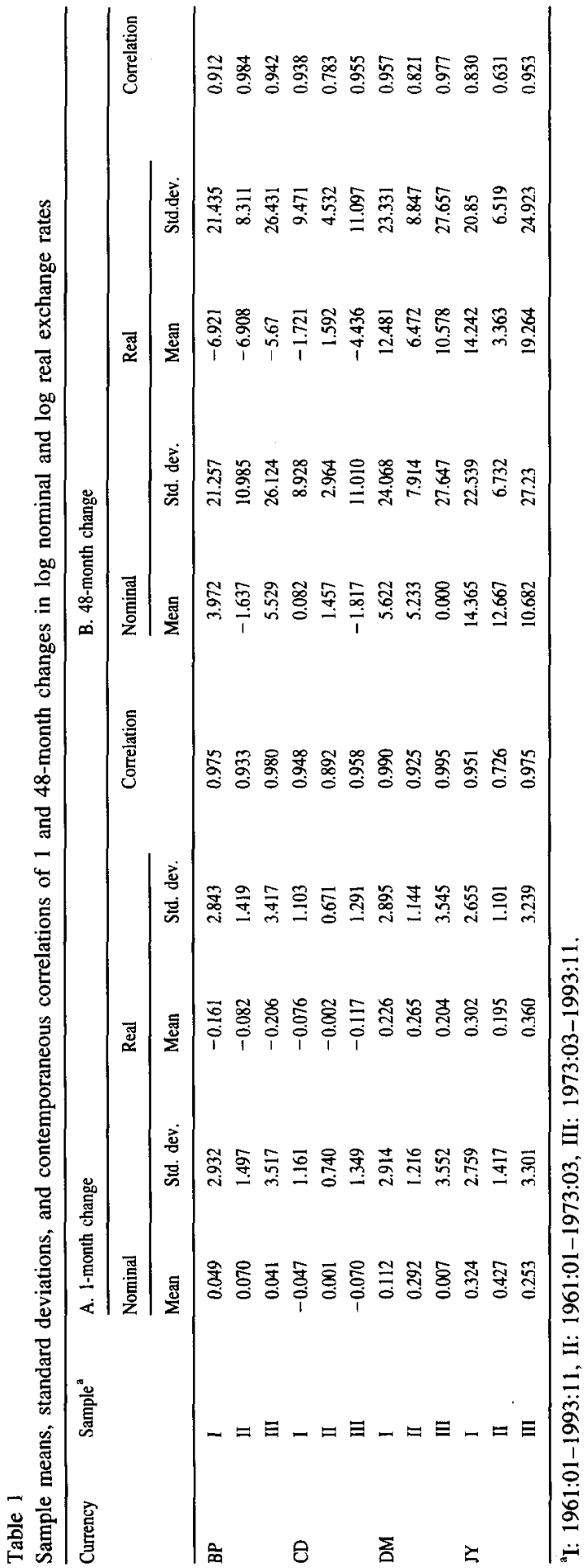




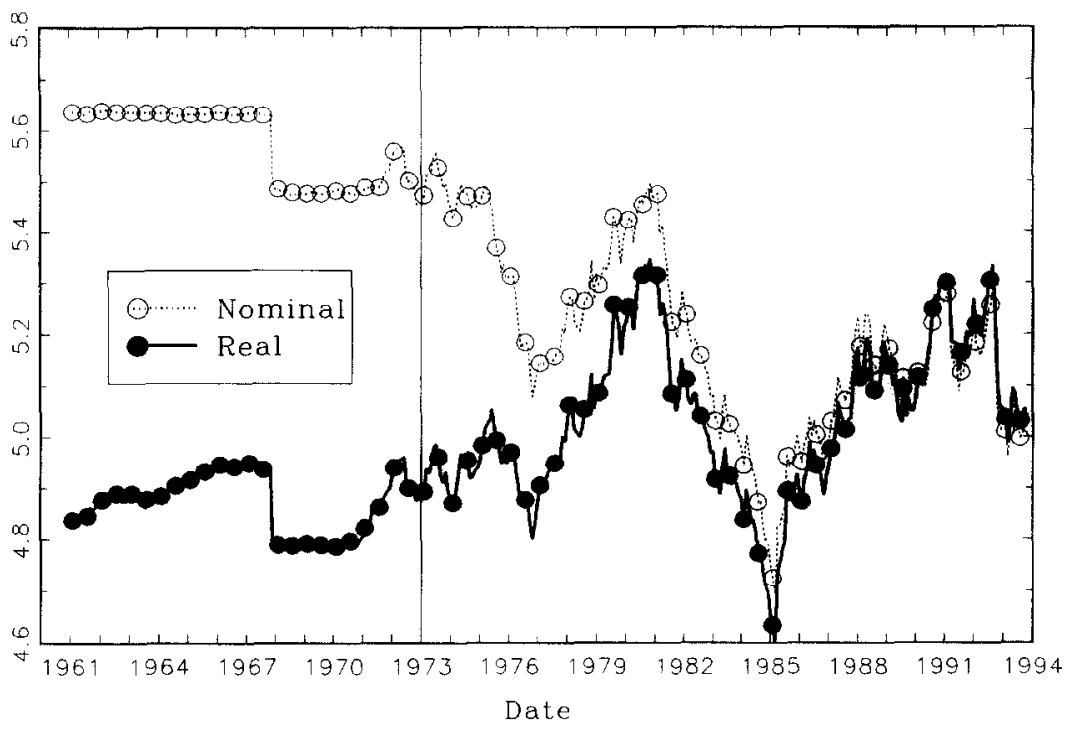

Fig. 1. Logarithms of real and nominal BP.

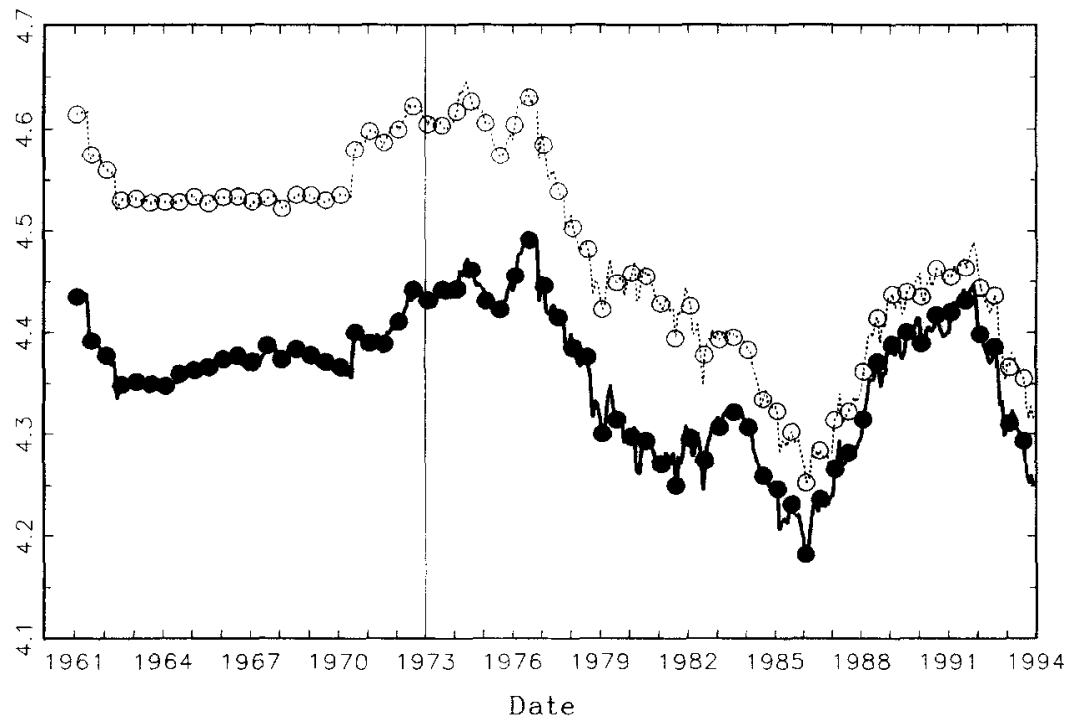

Fig. 2. Logarithms of real and nominal CD. 


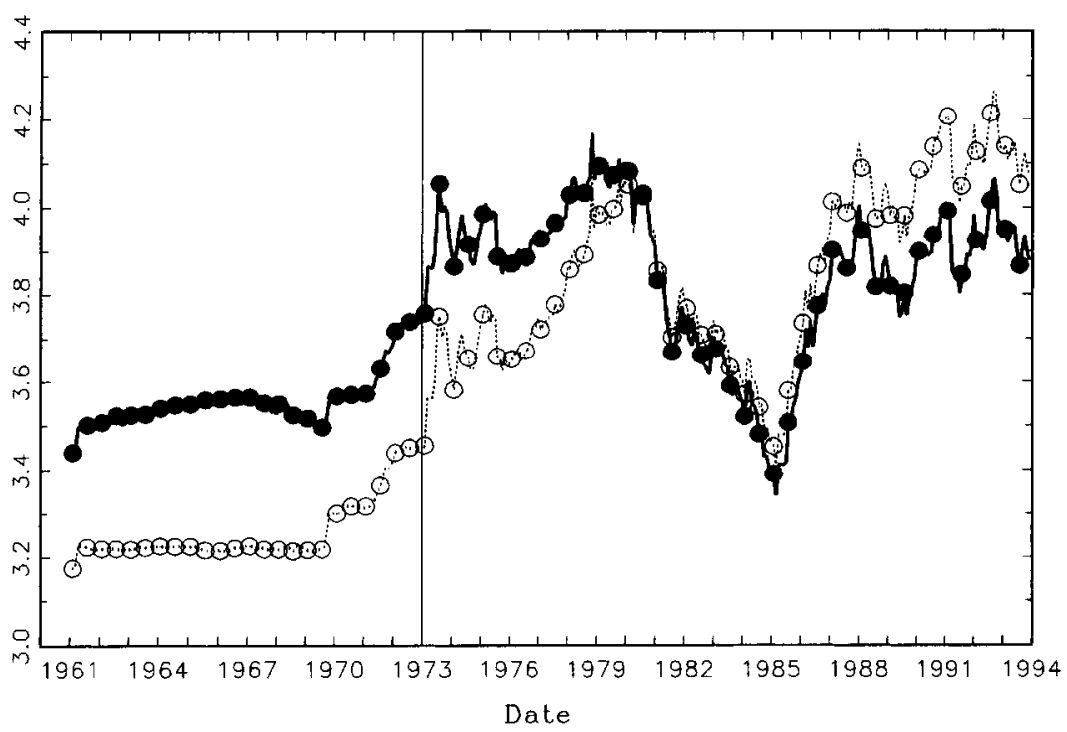

Fig. 3. Logarithms of real and nominal DM.

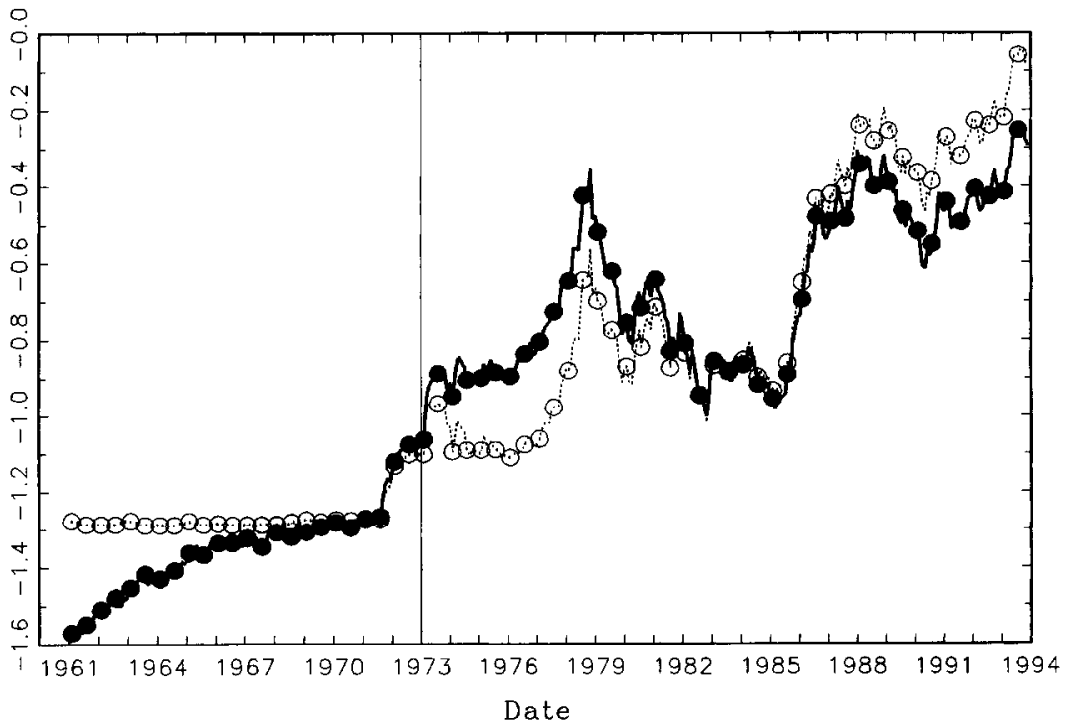

Fig. 4. Logarithms of real and nominal JY. 
horizon. ${ }^{16}$ We fix the forecast period to extend from 1985:01 to 1993:11 with the initial forecast formed using data available through 1981:01. In generating the 107 overlapping predictions, we consider two estimation periods. The first begins with the move to generalized floating in 1973:03 while the second begins in 1961:01.

Panel A of Table 2 reports results using post-float data. The 'out/RW' values are the least-squares root MSPEs relative to those of the driftless random walk. The numbers in parentheses are Diebold and Mariano (1995) test statistics which we normalize to be positive when the regression has a lower MSPE. Here, we find little evidence against the hypothesis that the log real exchange rate follows a random walk, as only 4 of the 28 entries lie below one, and none significantly so. The constant value fundamental implied by PPP displays predictive power only for the $\mathrm{BP}$ (out $/ \mathrm{RW}=0.70, t=1.80$ ). Point predictions based on productivity differentials augmented with government spending ratios beat the random walk for the $\mathrm{CD}$ (out/RW $=0.87$ ), while the ad hoc monetary model forecasts slightly outperform the random walk for the $\mathrm{CD}$ (out $/ \mathrm{RW}=0.89$ ) and the $\mathrm{JY}$ (out $/ \mathrm{RW}=0.98$ ).

The regression's in-sample root mean square error over the forecast period relative to the out-of-sample root MSPE, (labeled 'in/out') generally lie below one. These small in/out values indicate that prediction is hampered by the rather large sampling error of the estimated coefficients. For example, the in/out value of 0.29 for the DM's in sample productivity differential regression in column (ii) implies a root mean square error relative to the random walk of 0.60 over the period 1985:01-1993:11. We note also that the deterioration for the BP seen in column (i) when going to the full sample is evidence against long-run PPP since acquiring more data should lead to improvements in fit if the model is true.

We are able to significantly reduce the sampling error by extending the data back to 1961. With the exception of the PPP forecasts for the BP and CD, and CD predictions from the productivity and relative income models (columns (ii)-(iv)), the Out/RW entries in panel B lie far below their panel A counterparts. The deterioration of the out-of-sample forecast errors relative to the in-sample errors has also been reduced as indicated by the relatively large in/out values.

Looking across the columns, many of the alternative fundamentals enjoy some degree of support. Although not significant at the 5\% level, the following seem to work: the PPP fundamental for BP, DM, and JY; $\log$ productivity differentials with $\log$ government spending ratios for the $\mathrm{CD}$ and JY; log per capita income differentials and real interest-rate differentials for the BP, DM, and JY. However, only the deviation of the nominal exchange rate from its fundamental value suggested by Frankel's expectations rule and the ad hoc monetary model fundamentals outperform the random walk for all four real exchange rates.

\footnotetext{
${ }^{16}$ It has been well documented in the literature that short-horizon changes in nominal (e.g. Meese and Rogoff, 1983; Engel and Hamilton, 1990; Diebold and Nason, 1990; Engel, 1994) or real exchange rates (Meese and Rogoff, 1988) are nearly unpredictable. The short-horizon predictions from our regressions confinn this well-known fact and are not reported to save on space.
} 


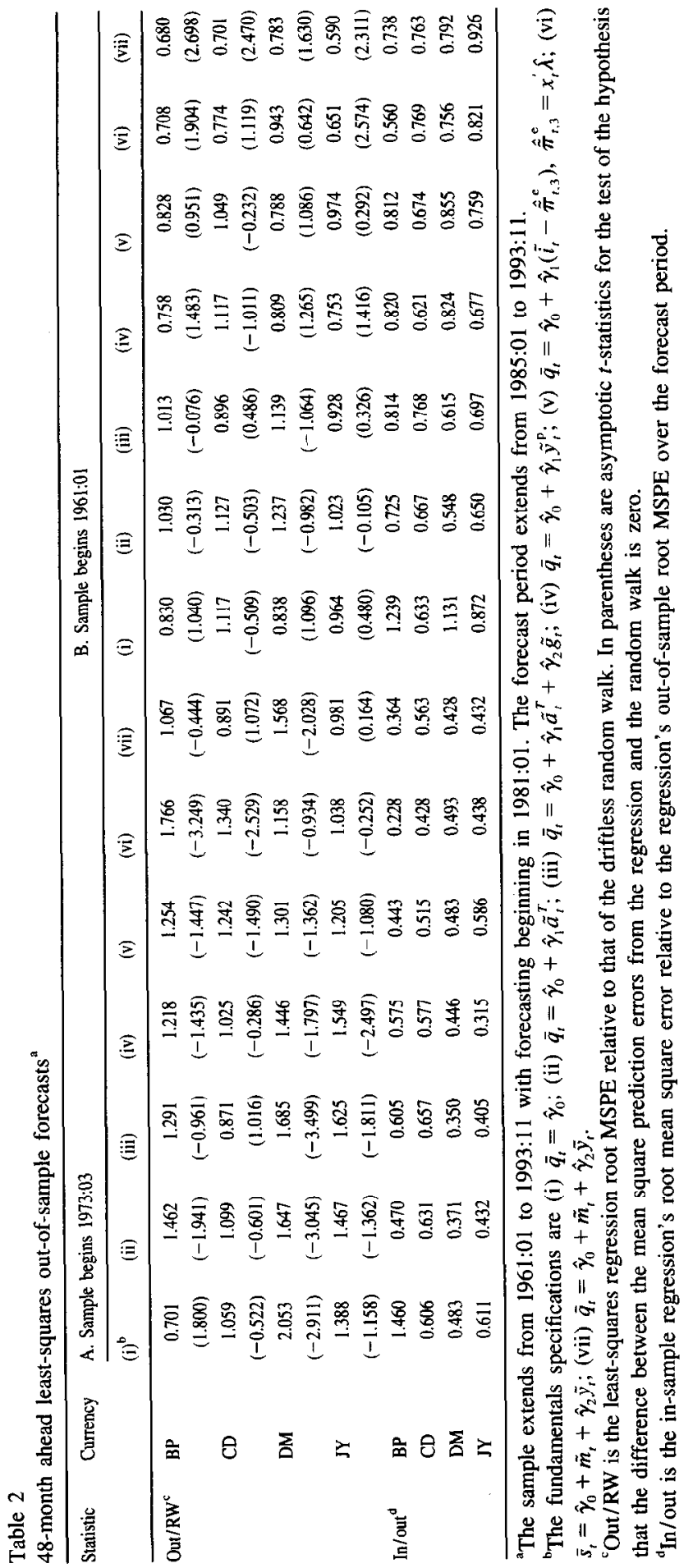


Significant forecasts are obtained for the JY under the Frankel fundamentals and for the BP, CD, and JY under the ad hoc monetary model fundamentals.

We have found that forecasts based on monetary model fundamentals outperform the random walk. Do they also outperform the PPP forecasts? Except for the DM, the answer is yes. The root MSPEs (Diebold-Mariano $t$-ratios) of the Frankel model regression relative to the PPP regression are 0.819 (1.286), 0.957 $(0.199), 1.210(-3.137)$, and 0.651 (3.269) for the BP, CD, DM, and JY respectively. The corresponding values for the ad hoc monetary model relative to PPP are 0.787 (2.399), 0.866, (0.937) $1.004(-0.341)$, and 0.589 (2.737).

\subsection{Least-squares full-sample estimates}

The evidence suggests that the Frankel model and the ad hoc monetary model fundamentals provide the best long-horizon predictions. Thus, to save on space, we report estimation results only for these two representations. Table 3 reports long-horizon and backward average regressions estimated over the full sample 1961:01-1993:11.

Looking first at the long-horizon regressions, the estimated slope coefficients, asymptotic $t$ (which we compute using Newey and West (1994)) and $R^{2}$ exhibit the familiar pattern of increasing, at least initially, with the forecast horizon. The strongest evidence that the log real exchange rate is predictable comes at the 36 and 48-month horizon. For example, looking at the ad hoc monetary model for the $J Y$, increasing the horizon from 3 to 48 months leads the slope coefficient to increase from 0.03 to 0.56 , the asymptotic $t$-ratio from 1.5 to 6.65 , and the $R^{2}$ from 0.03 to 0.58 . For the $\mathrm{CD}$, the $R^{2}$ display a hump-shape reaching its maximum at the 36-month horizon while the largest $R^{2}$ are found at the 48-month horizon for the BP, DM, and JY.

The implied speeds of adjustment are generally consistent across horizons and are somewhat higher than typically found in long-run PPP estimates. For example, under the ad hoc monetary model fundamentals, the average annual speed of adjustment implied by the 12-month horizon estimates is 0.17 whereas the 48 -month horizon estimates imply a value of 0.15 , or a half-life of 3.2 years.

Taken at face value, the hypothesis of no predictability is easily rejected based on the asymptotics at $k=48$. However, as discussed above, tests based on these asymptotic $t$-ratios are suspected to be unreliable due to severe small sample size distortion.

To get reliable tests of the hypothesis that changes in the log real exchange rate are unpredictable, we turn to the backward average regressions. Here, the small $R^{2}$ are typical of 1-month-ahead log exchange-rate regressions. As was the case with the long-horizon regressions, the slope coefficients and asymptotic $t$-ratios are seen to increase with the horizon. Using Hodrick's calculation that the empirical critical value is approximately 2.0 for a one-tail test with $5 \%$ size, we can reject the null hypothesis that the log real exchange rate is unpredictable at either the three or 


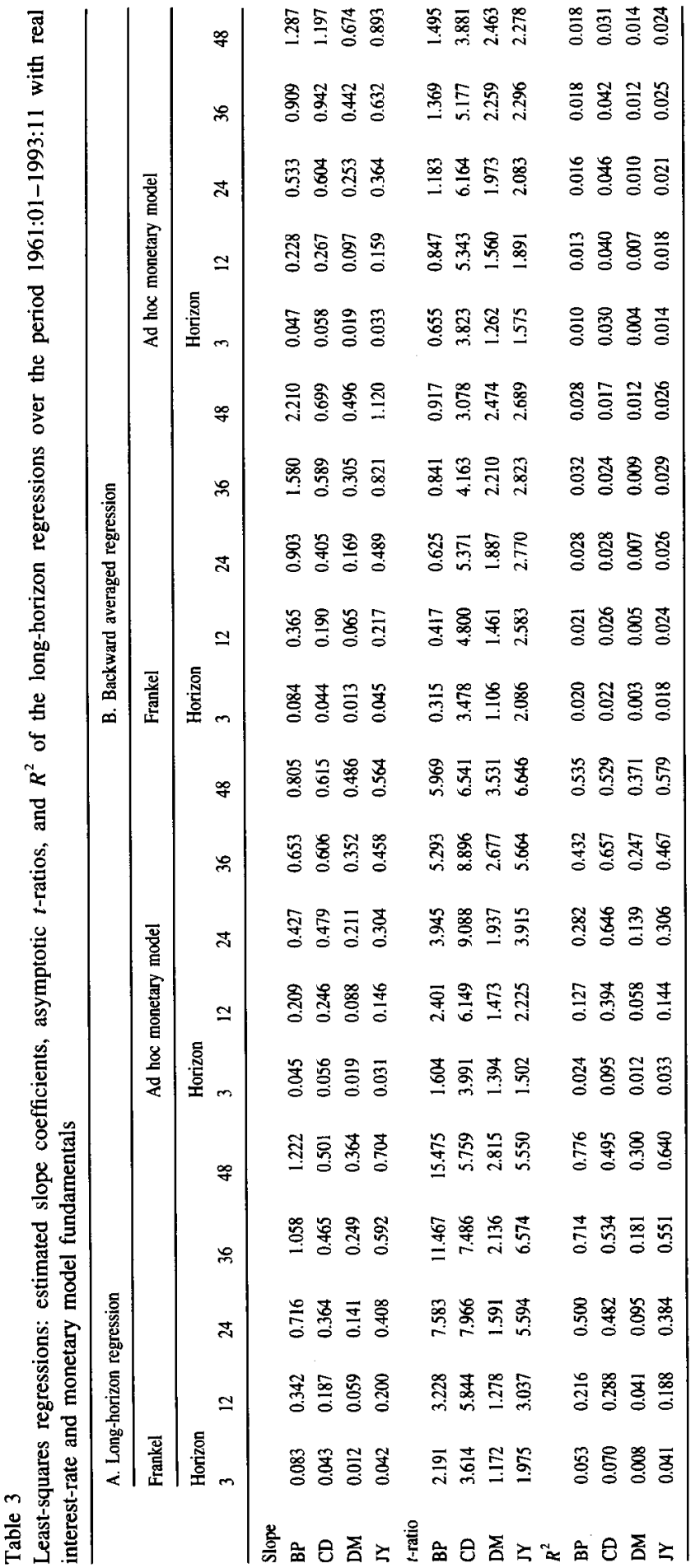




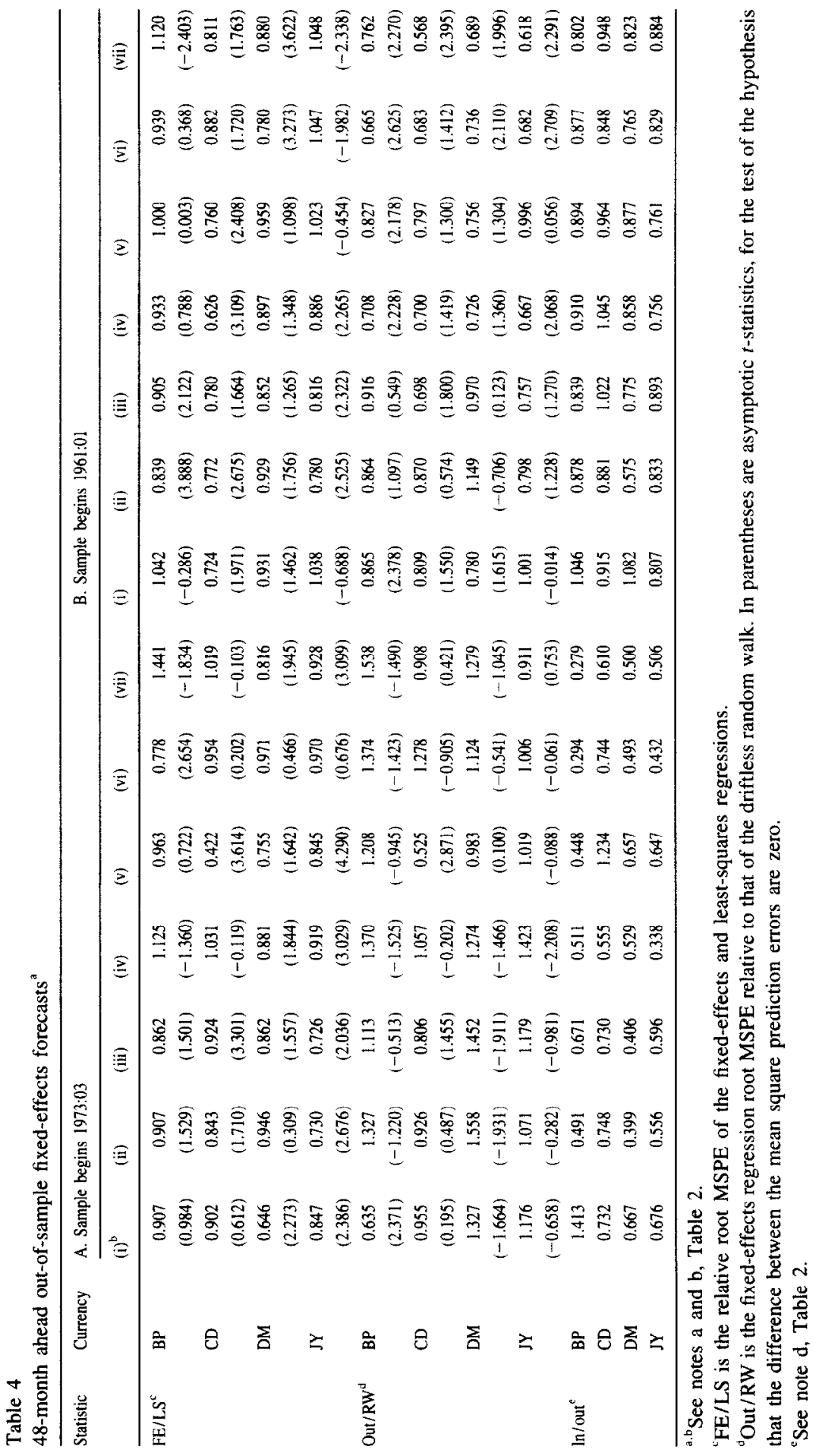


four-year horizon for the CD, DM, and JY based upon either the Frankel or the ad hoc monetary model fundamentals. ${ }^{17}$

\subsection{Fixed-effects out-of-sample forecasts}

Panel A of Table 4 reports results using the post-float data. We begin by reporting the relative root MSPEs of the fixed-effects regression relative to least squares (labeled FE/LS). Pooling is generally seen to improve prediction accuracy as 24 of the 28 entries lie below 1 with 10 of the entries having $t$-ratios exceeding 2.0. While they dominate the least-squares predictions, the fixed-effects forecasts are not stunningly accurate. Out/RW values for the BP under PPP and real interest-rate differentials for the CD lie below 1 but neither of these values is significant. The small in/out values show substantial deterioration in the out-ofsample forecast's precision relative to the in-sample fit.

Extending the sample back to 1961:01 (panel B), the FE/LS values again illustrate the benefits of pooling as 22 of the 28 entries lie below 1, with 10 of the entries having $t$-ratios exceeding 2.0. Looking at the out/RW values, we see that each of the alternative fundamentals specifications enjoys some measure of support. Regressions using the PPP and productivity differentials fundamentals beat the random walk for three of the four currencies while the fundamentals from the augmented productivity model, per capita income differentials, real interest differentials and monetary models dominate the random walk for all four currencies. Once again, however, monetary model based fundamentals (columns (vi) and (vii)) produce the largest and most significant improvements over the random walk. The predictions from the Frankel model are significant for the BP, DM, and JY, while the ad hoc monetary model predictions are significant at the $5 \%$ level for all four currencies.

The point predictions from both of the monetary model regressions also dominate the PPP forecasts. The MSPEs (asymptotic $t$-ratios) from the Frankel model relative to PPP are 0.769 (2.154), $0.845(0.726), 0.944$ (0.567), 0.681 (3.363) for the BP, CD, DM, and JY respectively. The corresponding values for the ad hoc monetary model are 0.881 (1.379), 0.703 (1.927), 0.884 (3.555), and 0.617 (2.730).

\footnotetext{
${ }^{17}$ Richardson and Stock (1989) and Hodrick (1992) argue that to test the hypothesis that the log real exchange rate is predictable requires a test that the slope coefficients at each horizon are jointly zero. We are interested in the narrower question precisely whether the log real exchange rates are predictable at the 48-month horizon. Moreover, Campbell (1993) argues that asymptotic power improves as the horizon is lengthened and Shiller and Perron (1985) make the same point in a different context. We do not pertorm this joint test as the low power inherent in tests of predictability at the short horizons will become impounded into the joint test.
} 


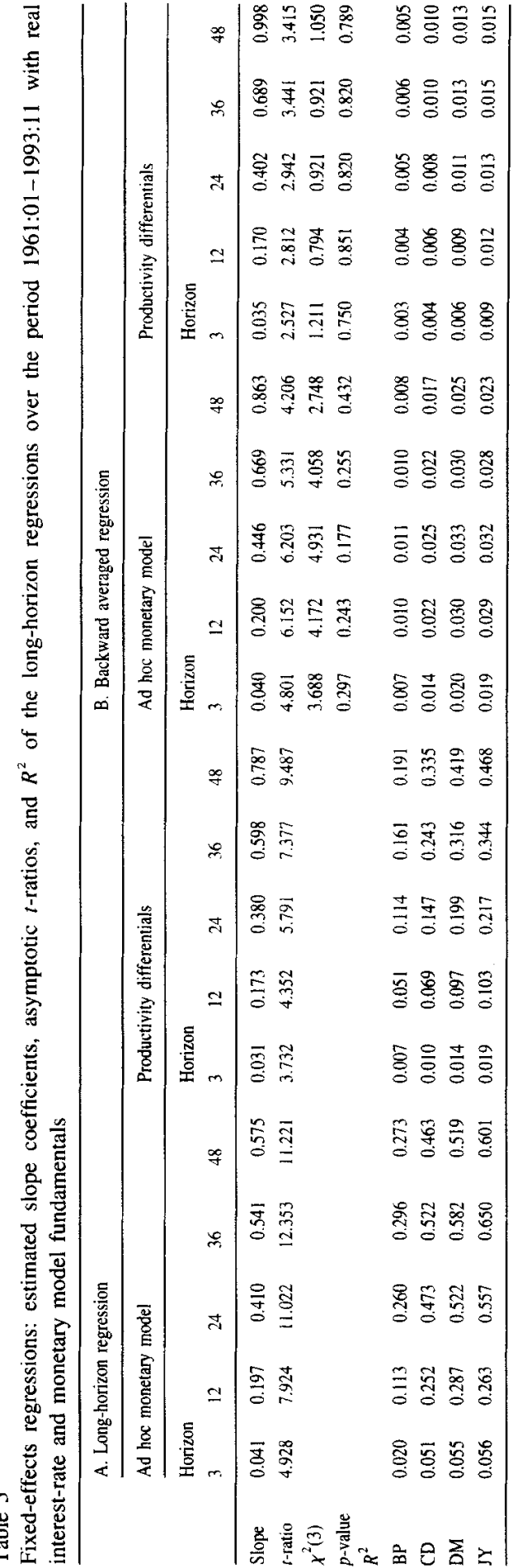




\subsection{Fixed-effects full-sample estimates}

We find that the full-sample estimates across the alternative fundamentals are qualitatively similar. To use less space, we report in Table 5 the full-sample estimates only for the ad hoc monetary model and productivity differentials. Again, the slope coefficients, asymptotic $t$, and $R^{2}$ from the long-horizon fixedeffect regressions increase with horizon. ${ }^{18}$ Under the ad hoc monetary model, the asymptotic $t$-ratio displays a hump, reaching a maximum at the 36-month horizon as do each of the $R^{2}$.

We plot the in-sample fitted values and out-of-sample forecasts from the fixed-effects regressions with the ad hoc monetary model fundamentals along with the actual four-year changes in $q_{t}$ in Fig. 5 Fig. 6 Fig. 7 Fig. 8. As can be seen, divergence between the fitted and forecasted values is largely eliminated by 1988 .

Turning to the backward average regressions, the slope coefficients are seen to increase with horizon while the asymptotic $t$-ratios peak at 36 -months. We conduct a Wald test of the hypothesis that the slope coefficients in the backward average regression are equal across currencies. The Wald statistics are reported as $\chi^{2}(3)$ and the large $p$-values offer little evidence that pooling is inappropriate. Finally,

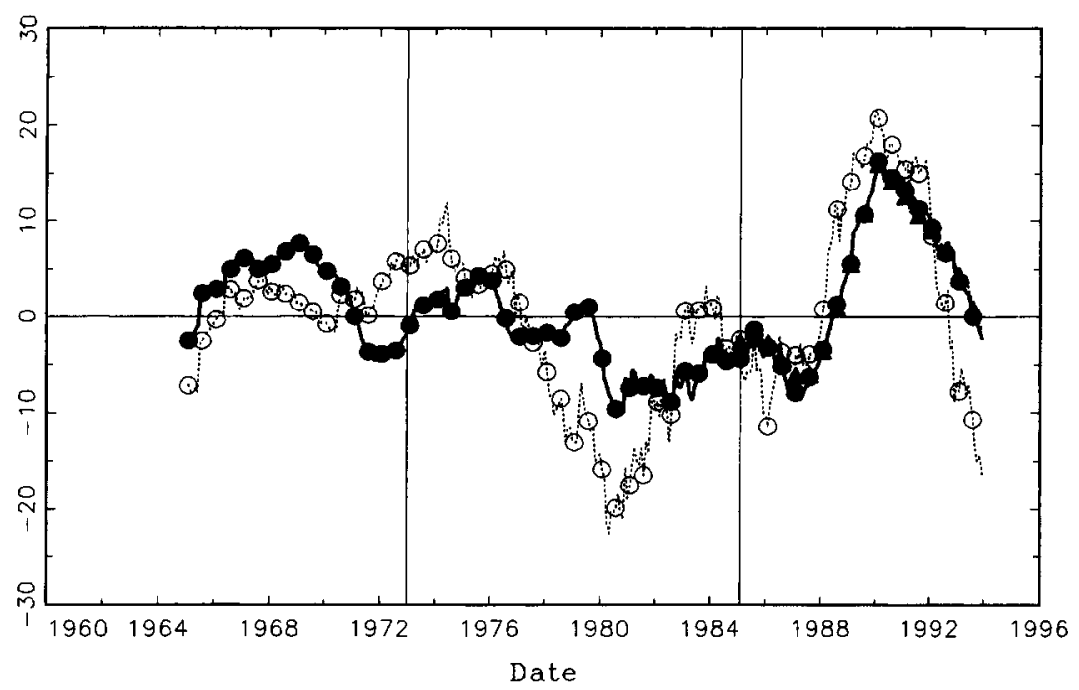

Fig. 6. CD fixed-effects fitted values, forecasts, and actual four-year changes. $O$ actual; $\bigcirc$ FE-in; $\Delta$ FE-out.

\footnotetext{
${ }^{18}$ Because the orthogonality conditions are not set exactly to zero in the GMM estimates, there are two ways to compute the $R^{2}$. The values reported are the fraction of total variation explained by the fitted value.
} 


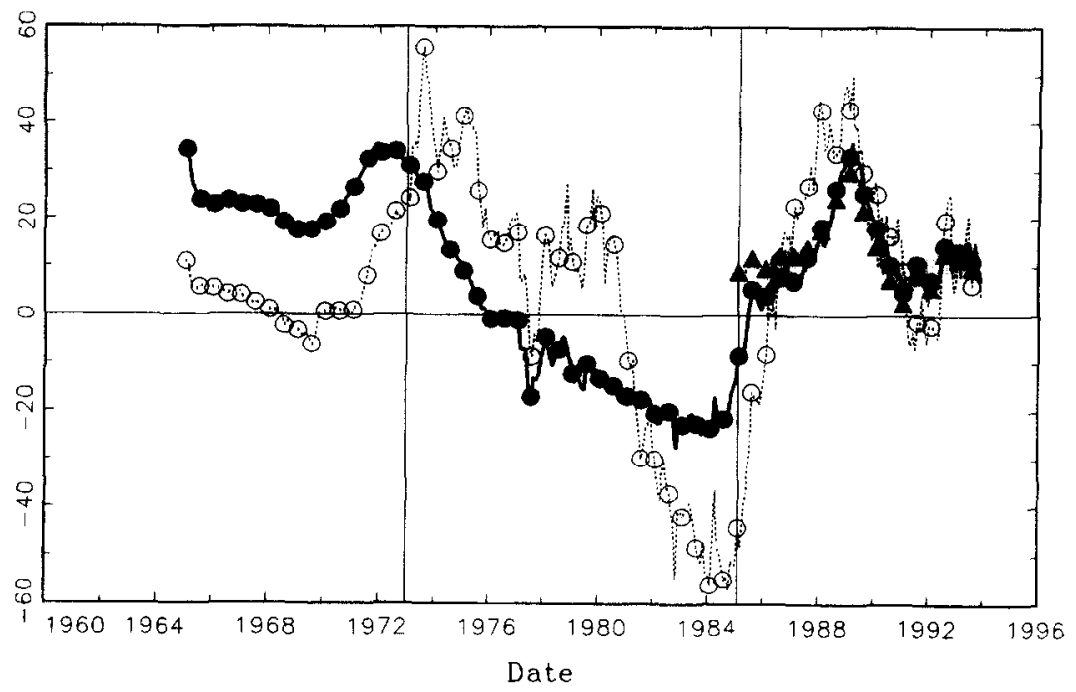

Fig. 7. DM fixed-effects fitted values, forecasts, and actual four-year changes. $O$ actual; 1 FE-in; $\Delta$ FE-out.

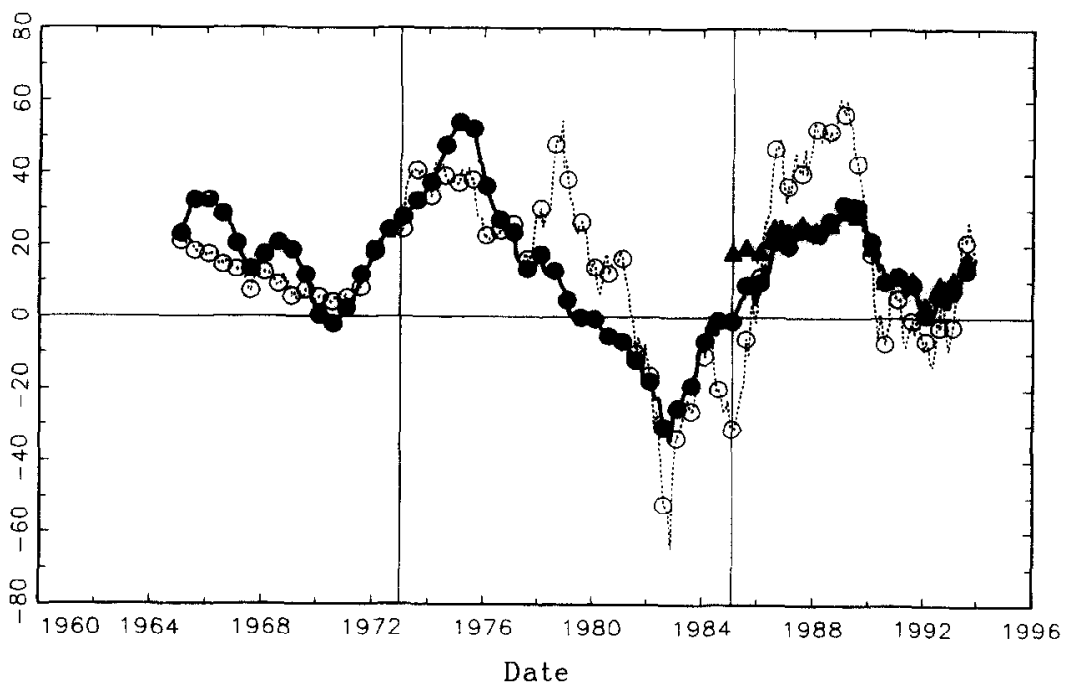

Fig. 8. JY fixed-effects fitted values, forecasts, and actual four-year changes. $O$ actual; - FE-in; $\wedge$ FE-out. 


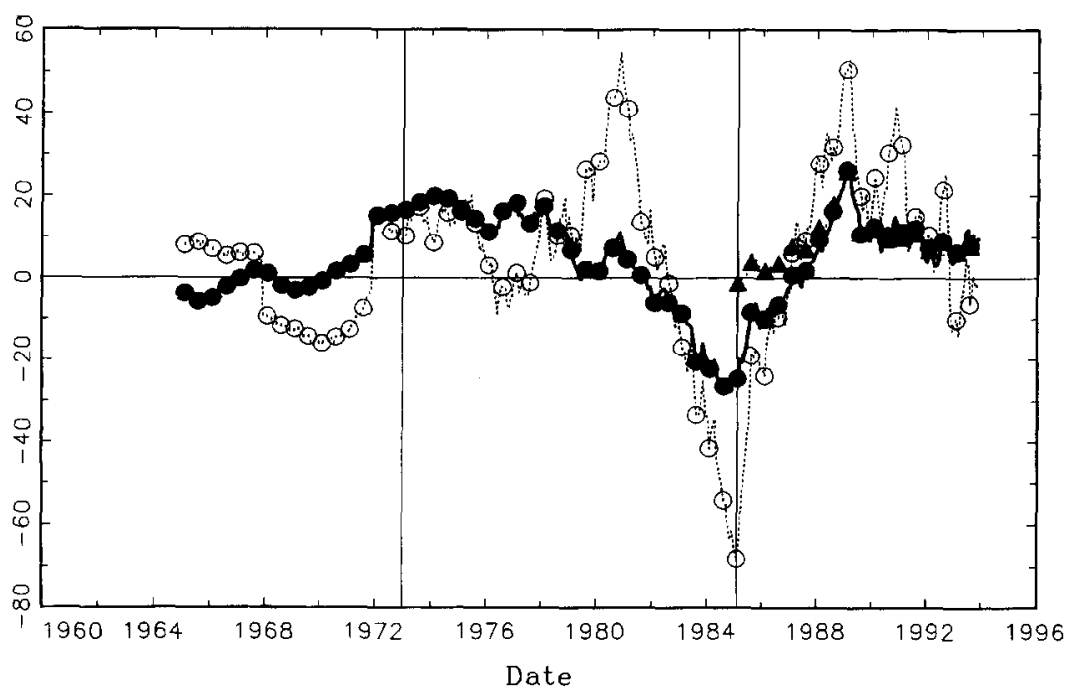

Fig. 5. BP fixed-effects fitted values, forecasts, and actual four-year changes. $O$ actual; $\bigcirc$ FE-in; FE-out.

the asymptotic $t$-ratios at any of the horizons considered easily reject the hypothesis that the log real exchange rate is unpredictable.

\section{Concluding remarks}

In this paper, we model the log real exchange rate as the sum of permanent and transitory components. Variables suggested by economic theory are used to characterize the permanent part which we interpret as the long-run equilibrium value of the real exchange rate. Combining aspects of the random walk and PPP models in this way turns out to be useful in that the implied transitory components are found to contain significant predictive power for four-year changes in the log real exchange rate between the US and four industrialized countries.

It is important to look over long horizons, since earlier work, as well as our own unreported results, finds that the real exchange rate is essentially unpredictable at horizons of 3 and 12 months. The message is that short-horizon changes in log real exchange rates are dominated by noise, but because real exchange rates are ultimately governed by economic fundamentals, these noisy fluctuations reverse themselves over time.

Our prediction results also underscore the point that many earlier attempts to understand and to predict real exchange-rate dynamics were hampered because the time span of the data analyzed was not sufficiently long to obtain reliable parameter cstimates. Using a fixed forecast period, we generally find that 
prediction accuracy improves when we exploit additional data by extending the sample backwards and cross-sectionally. We find improvement in spite of there being an obvious change in the volatility of real exchange-rate changes in 1973 associated with the adoption of generalized floating.

While we can easily reject the random walk, our results also indicate that we need to go beyond PPP to understand the evolution of real exchange rates. Productivity differentials, real interest-rate differentials, and per capita income differentials all enjoy some measure of support in the out-of-sample prediction exercises. But it turns out that the most accurate and statistically significant predictions are generated by the deviation of the nominal exchange rate from its fundamental value as suggested by Frankel's expectations rule and an ad hoc application of the simple monetary model to the log real exchange rate. On the one hand, it is not so remarkable that monetary variables contain predictive power for real exchange rates since this is what is implied by sticky-price models. ${ }^{19}$ What is surprising is that monetary variables seem to explain variation in the long-run equilibrium real exchange rate. The apparent non-neutrality that this implies could be viewed as a shred of evidence for the presence of hysteretic effects. ${ }^{20}$

\section{Acknowledgments}

We thank Richard Baillie, Charles Engel, Masao Ogaki and seminar participants at the Federal Reserve Bank of St. Louis and York University for useful comments on an earlier draft, and Stephen Cecchetti for a useful conversation. The thoughtful comments of two anonymous referees led to improvements in the paper.

\section{Appendix A}

We employed data obtained from the OECD Main Economic Indicators (MEI), CITIBASE, the Harris Bank Foreign Exchange Weekly Review (Harris), and International Financial Statistics, (IFS). We collected observations beginning in 1960:01. Regardless of whether the data were seasonally adjusted at the source, observations used in the empirical work were formed by taking a moving average of the current and 11 lagged monthly observations. Thus, estimation over the full sample hegins in 1961:01.

\footnotetext{
${ }^{19}$ Using vector autoregression techniques, Eichenbaum and Evans (1995), Clarida and Gali (1994), and Rogers (1995) have found that monetary shocks have persistent effects on real exchange rates. See also Engel (1994) and Engel and Rogers (1995) who interpret their evidence as supportive of sticky-price models.

${ }^{20}$ Using different methods from ours, Rogers and Jenkins (1995) arrive at a similar conclusion.
} 


\section{Great Britain}

The consumer price index (CPI), nominal exchange rate, and seasonally adjusted industrial production, unadjusted manufacturing production and manufacturing employment data from (1960:01-1991:12) are taken from $M E I$ diskettes and from various issues (1992:01-1993:11). The short-term interest-rate series is constructed by splicing the call money rate from the MEI (1960:01-1966:12) to the 3-month euro pound rate from Harris (1967:01-1993:11). The long-term interest-rate series is the 20-year government bond yield from the $M E I$. The money series is from the IFS and is constructed in two steps. In the first step, a series was formed by splicing together the money index (series 11234.IZF, from 1960:011969:05) to M0 (series 11259MC.2F, available from 1969:06-1993:11). Monthly government consumption to GDP ratios are formed by linear interpolation of quarterly observations from the IFS.

\section{Canada}

The CPI, seasonally adjusted M1, unadjusted manufacturing production, manufacturing employment data, and the nominal exchange rate are from the $M E I$ diskettes (1960:01-1992:03) and various issues (1992:04-1993:11). From 1960:01-1992:03, seasonally adjusted industrial production is from CITIBASE, and from 1992:04-1993:11 is from various issues of the $M E I$. The short-term interest rate is constructed by splicing the 90-day prime corporate paper rate (1960:01-1066:12) from the MEI to the 3-month euro Canadian dollar rate (1967:01-1993:11) from Harris, while the long-term rate from the $M E I$ is the yield on federal government bonds with maturity greater than 10 years. Monthly government consumption to GDP ratios are formed by linear interpolation of quarterly observations from the IFS.

\section{Germany}

The CPI, seasonally adjusted industrial production, seasonally adjusted M1, unadjusted manufacturing production, manufacturing employment data, and the nominal exchange rate are from the MEI diskettes (1960:01-1992:03) and from various issues (1992:04-1993:11). The short-term interest-rate series is formed by combining the 3-month Frankfort inter-bank offer rate (1960:01-1966:12) from the $M E I$ with the Harris 3-month euro deutsche mark rate (1967:01-1993:11). Monthly government consumption to income ratios are formed by linear interpolation of quarterly observations from the IFS.

\section{Japan}

The CPI and seasonally adjusted industrial production are from CITIBASE. Seasonally adjusted M1, unadjusted manufacturing production index, manufactur- 
ing employment data, and the nominal exchange rate comes from the $M E I$ diskettes (1960:01-1992:03) and various issues (1992:04-1993:11). The shortterm interest-rate series is formed by combining the call money rate from $M E I$ (1960:01-1975:09) with the 3-month euro yen rate from Harris (1975:101993:11). Monthly government consumption to gross national expenditure (GNE) ratios are formed by linear interpolation of quarterly observations from the IFS.

\section{United States}

Unadjusted manufacturing production and manufacturing employment data are from the $M E I$ diskettes (1960:01-1992:03) and various issues (1992:04-1993:11). Seasonally adjusted M1, industrial production, and CPI data are from CITIBASE. The short-term interest-rate series is formed by combining the yield on 3-month US Treasury bills in the secondary market (CITIBASE, 1960:01-1966:12) with the 3-month euro dollar rate (Harris, 1967:01-1993:11). The long-term interest is taken from CITIBASE and are yields for US treasury bonds with 10 years to maturity. Monthly government expenditure less gross capital formation to GDP ratios are formed by linear interpolation of quarterly observations from the IFS.

\section{References}

Abel, A., 1990, Asset prices under habit formation and catching up with the Joneses, American Economic Review 80, 38-42.

Abuaf, N. and P. Jorion, 1990, Purchasing power parity in the long run, Journal of Finance 45, $157-174$.

Adler, M. and B. Lehman, 1983, Deviations from purchasing power parity in the long run, Journal of Finance $39,1471-1487$.

Balassa, B., 1964, The purchasing-power parity doctrine: A reappraisal, Journal of Political Economy 72, 584-596.

Baxter, M., 1994, Real exchange rates and real interest differentials: Have we missed the businesscycle relationship?, Journal of Monetary Economics 33, 537.

Bleaney, M. and P. Mizen, 1995, Empirical tests of mean reversion in real exchange rates: A survey, Bulletin of Economic Research 47, 171-195.

Blough, S.R., 1992, The relationship between power and level for generic unit root tests in finite samples, Journal of Applied Econometrics 7, 295-308.

Breuer, J.B., 1994, An assessment of the evidence on purchasing power parity, in: J. Williamson, ed., Estimating equilibrium exchange rates, (Institute for International Economics, Washington D.C.) 245-277.

Campbell, J.Y., 1993, Why long horizons? Power against persistent alternatives, Working Paper (Princeton University).

Campbell, J.Y. and R.H. Clarida, 1987, The dollar and real interest rates, Carnegie-Rochester Conference Series on Public Policy 27, 103-140.

Campbell, J.Y. and R.J. Shiller, 1988, Stock prices, earnings, and expected dividends, Journal of Finance 43, 661-676.

Chinn, M.D., 1994, Paper pushers or paper money? Empirical assessment of fiscal and monetary models of exchange rate determination, Working Paper (UC Santa Cruz). 
Chinn, M.D. and R.A. Meese, 1995, Banking on currency forecasts: How predictable is change in money?, Journal of International Economics 38, 161-178.

Clarida, R.H. and J. Gali, 1994, Sources of real exchange rate fluctuations: How important are nominal shocks?, Carnegie-Rochester Conference Series on Public Policy 41, 1-56.

Cochrane, J.H., 1991, A critique of the application of unit root tests, Journal of Economic Dynamics and Control 15, 275-284.

Cumby, R.E., 1988, Is it risk? Explaining deviations from uncovered interest parity, Journal of Monetary Economics 22, 279-299.

Cumby, R.E. and J. Huizinga, 1991, The predictability of real exchange rate changes in the short and long run, Japan and the World Economy 3, 17-38.

DeGregorio, J. and H.C. Wolf, 1994, Terms of trade, productivity, and the real exchange rate, Working Paper 4807 (National Bureau of Economic Research).

Diebold, F.X. and R.S. Mariano, 1995, Comparing predictive accuracy, Journal of Business and Economic Statistics 13, 253-263.

Diebold, F.X. and J.A. Nason, 1990, Nonparametric exchange rate prediction?, Journal of International Economics 28, 315-332.

Diebold, F.X., S. Husted and M. Rush, 1991, Real exchange rates under the gold standard, Journal of Political Economy 99, 1252-1271.

Dornbusch, R., 1976, Expectations and exchange rate dynamics, Journal of Political Economy 84, $1161-1176$.

Edison, H.J., 1987, Purchasing power parity in the long run: A test of the dollar/pound exchange rate (1890-1978), Journal of Money, Credit and Banking 19, 376-387.

Edison, H.J. and W.R. Melick, 1995, More empirical evidence on real exchange rates and real interest rate differentials, Working Paper (Division of International Finance, Federal Reserve Board).

Edison, H.J. and B.D. Pauls, 1993, A reassessment of the relationship between real exchange rates and real interest rates: 1974-1990, Journal of Monetary Economics 31, 165-187.

Eichenbaum, M.S. and C. Evans, 1995, Some empirical evidence on the effects of monetary policy shocks on exchange rates, Qurarterly Journal of Economics 110, 975-1009.

Eichenbaum, M.S., L.P. Hansen and K.J.Singleton, 1988, A time series analysis of representative agent models of consumption and leisure choice under uncertainty, Quarterly Journal of Economics 103, $51-78$.

Engel, C.M., 1993, Real exchange rates and relative prices: An empirical investigation, Journal of Monetary Economics 32, 35-50.

Engel, C. M., 1994, Can the Markov-switching model forecast exchange rates?, Journal of International Economics 36, 151-165.

Engel, C.M. and J.D. Hamilton, 1990, Long swings in the dollar: Are they in the data and do markets know it?, American Economic Review 80, 689-713.

Engel, C. and J.H. Rogers, 1995, How wide is the border?, Working Paper (University of Washington).

Fama, E.F. and K.R. French, 1988, Dividend yields and expected stock returns, Journal of Financial Economics 22, 3-25.

Frankel, J.A., 1979, On the mark: A theory of floating exchange rates based on real interest differentials, American Economic Review 69, 610-1074.

Frankel, J. and A.K. Rose, 1996, A panel project on purchasing power parity: Mean reversion within and between countries, Journal of International Economics 40, 209-224.

Froot, K.A. and K. Rogoff, 1996, Perspectives on PPP and long-run real exchange rates, in: G. Grossman and K. Rogoff, eds., Handbook of International Economics, Vol. 3 (North-Holland, Amsterdam).

Grilli, V. and G. Kaminsky, 1991, Nominal exchange rate regimes and the real exchange rate: Evidence from the United States and Great Britain, 1885-1986, Journal of Monetary Economics 27, 191-212.

Hakkio, C., 1984, A reexamination of purchasing power parity, Journal of International Economics 17, 265-277. 
Hodrick, R.J., 1989, Risk, uncertainty, and exchange rates, Journal of Monetary Economics 23, 433-459.

Hodrick, R.J., 1992, Dividend yields and expected stock returns: Alternative procedures for inference and measurement, Review of Financial Studies 5, 357-386.

Hsieh, D., 1982, The determination of the real exchange rate: The productivity approach, Journal of International Economics 12, 355-362.

Huizinga, J., 1987, An empirical investigation of the long run behavior of real exchange rates, Carnegie-Rochester Conference Series on Public Policy 27, 149-214.

Jegadeesh, N., 1991, Seasonality in stock price mean reversion: Evidence from the US and the UK, Journal of Finance 46, 1427-1444.

Kakkar, V. and M. Ogaki, 1994, Real exchange rates and nontradables: A relative price approach, Working Paper (Ohio State University).

Kim, Y., 1990, Purchasing power parity in the long run: A cointegration approach, Journal of Money, Credit and Banking 22, 491-503.

Lothian J.R. and M.P. Taylor, 1996, Real exchange rate behavior: The recent float from the perspective of the past two centuries, Journal of Political Economy 3, 488-509.

Lucas, R.E., Jr., 1982, Interest rates and currency prices in a two-country world, Journal of Monetary Economics 10, 335-359.

Mark, N.C., 1990, Real and nominal exchange rates in the long run: An empirical investigation, Journal of International Economics 28, 115-136.

Mark, N.C., 1995, Exchange rates and fundamentals: Evidence on long-horizon predictability, American Economic Review 85, 201-218.

Meese, R. and K. Rogoff, 1983, Empirical exchange rate models of the 1970s: Do they fit out of sample?, Journal of International Economies 14, 3-24.

Meese, R. and K. Rogoff, 1988, Was it real? The exchange-rate interest differential relation over the modern floating-rate period, Journal of Finance 43, 933-948.

Mishkin, F.S., 1981, The real interest rate: An empirical investigation, Carnegie-Rochester Conference Series on Public Policy 15, 151-200.

Mussa, M., 1986, Nominal exchange rate regimes and the behavior of real exchange rates: Evidence and implications, Carnegie-Rochester Conference Series on Public Policy 25, 117-213.

Nelson, C.R. and M.J. Kim, 1993, Predictable stock returns: The role of small sample bias, Journal of Finance 48, 641-661.

Newey, W.K. and K.D. West, 1987, A simple, positive semi-definite, heteroskedasticity and autocorrelation consistent covariance matrix, Econometrica 55, 703-708.

Newey, W.K. and K.D. West, 1994, Automatic lag selection in covariance matrix estimation, Review of Economic Studies 61, 631-653.

Obstfeld, M., 1993, Modeling trending real exchange rates, Working Paper (UC Berkeley).

Richardson, M. and J.H. Stock, 1989, Drawing inferences from statistics based on multiyear asset returns, Journal of Financial Economics 25, 323-348.

Rogers, J.H., 1995, Real shocks and real exchange rates in really long-term data, Working Paper (Federal Reserve Board).

Rogers, J.H. and M.A. Jenkins, 1995, Haircuts or hysteresis? Sources of movements in real exchange rates, Journal of International Economics 38, 339-360.

Rogoff, K., 1992, Traded goods consumption smoothing and the random walk behavior of the real exchange rate, Bank of Japan Monetary and Economic Studies 10, 1-29.

Rogoff, K., 1995, The purchasing power parity puzzle, Working Paper (Princeton University) July.

Roll, R., 1979, Violations of purchasing power parity and their implications for efficient international commodity markets, in: M. Samat and G.P. Szego, eds., International finance and trade (Ballinger, Cambridge, MA) 133-176.

Samuelson, P.A., 1964, Theoretical notes on trade problems, Review of Economics and Statistics 46, 145-154. 
Shilier, R.J. and P. Perron, 1985, Testing the random walk hypothesis: Power versus frequency of observation, Economics Letters 18, 381-386.

Stock, J.H. and M. Watson, 1993, A simple estimator of cointegrating vectors in higher order integrated systems, Econometrica 61, 783-820.

Wu, Y., 1996, Are real exchange rates non-stationary? Evidence from a panel-data test, Journal of Money, Credit and Banking 28, 54-63. 